\title{
O DIREITO DE IGUALDADE DE ALEXY E O CASO DOS MEDICAMENTOS PELO SUPREMO TRIBUNAL FEDERAL
}

\author{
Carolina Souza Mariz Maia Cabral ${ }^{161}$
}

Recebido em: 30/11/2016

Aprovado em: 28/10/2017

\begin{abstract}
RESUMO
O presente trabalho analisa o direito à saúde que consiste numa das garantias fundamentais listadas pela Constituição Federal, tendo o Estado o dever de assegurar o acesso universal e igualitário às ações e serviços para a promoção, proteção e recuperação da saúde. A complexidade da prestação do serviço de saúde transparece quando se percebe a incapacidade da Administração de provê-lo de forma integral para toda a sociedade. A judicialização da saúde foi provocada pela ineficiência do serviço, pois os indivíduos começaram a demandar a interferência do Judiciário para a resolução dos casos concretos. Porém, ao solucionar as situações individualizadas o magistrado assume o risco de violar a isonomia, dando espaço para injustiças. Robert Alexy na obra Teoria dos Direitos Fundamentais trata do direito geral de igualdade e traz os conceitos da igualdade fática e igualdade jurídica que devem ser assegurados pelo legislador e pelos tribunais. Com isso, é construído um paralelo entre a teoria de Alexy sobre o direito à igualdade fática e jurídica e o caso do fornecimento de medicamentos que está pendente de julgamento pelo Supremo Tribunal Federal. O reconhecimento da repercussão geral no RE 566.471 demonstra a relevância do tema para a sociedade brasileira que anseia pelo tratamento uniforme entre os usuários do Sistema Único de Saúde.
\end{abstract}

Palavras-chave: Direito à saúde. Igualdade. Alexy. Medicamentos. STF.

\section{INTRODUÇÃO}

A Constituição Federal de 1988 incorporou a tendência garantista do Estado Democrático de Direito ao tornar o Poder Público responsável pela oferta de diversos serviços. A Administração Pública brasileira atua de forma ampla na garantia dos direitos fundamentais dos cidadãos. Em alguns casos, foi permitida a atividade conjunta com

${ }^{161}$ Mestranda em Direito Constitucional pela UFRN. Pós-graduada em Direito Administrativo pela FGV-SP. Advogada. 
parceiros privados. O texto constitucional fixa os poderes, as obrigações e as formas de controle da Administração Pública, de modo a assegurar a concretização dos valores positivados. Desse modo, pretende manter a discricionariedade dos executores das políticas públicas circunscrita aos limites legais.

Naturalmente, as premissas do controle da Administração Pública se modificam conforme sua composição evolui, acompanhando as novas estruturas do direito brasileiro. Se antes a Administração era burocrática e agia estritamente de acordo com o texto legal, hoje se espera atuação gerencial e reinam os princípios da eficiência e efetividade. Nesse contexto, crescem as atividades das entidades privadas que colaboram com o Poder Público na prestação dos serviços previstos constitucionalmente. Logo, percebe-se o aumento proporcional das responsabilidades atribuídas ao Poder Público pelo texto constitucional e os novos laços criados com parceiros privados e entes da Administração Indireta.

A Constituição Federal em seu art. 197 dispõe como de relevância pública as ações e serviços de saúde, atribuindo ao Poder Público sua regulamentação, fiscalização e controle. Ainda neste dispositivo possibilita a execução do serviço através de terceiros, que podem ser pessoa física ou jurídica de direito privado. Além dos formatos de associações, sociedades, fundações e empresas individuais de responsabilidade limitada, as pessoas jurídicas de direito privado também podem ser estruturadas como entidades do terceiro setor e cooperativas, não possuindo estas duas a finalidade lucrativa.

É da competência do Poder Público a promoção de ações e serviços de saúde a serem prestados por órgãos e instituições públicas federais, estaduais e municipais, da Administração direta e indireta e das fundações mantidas pelo Poder Público. Todo este conjunto constitui o Sistema Único de Saúde (SUS) regrado pela Lei no 8.080/1990. Ao SUS são atribuídas inúmeras competências, entre elas, o controle e a dispensação de medicamentos à população.

A problematização da prestação da saúde revelou-se certamente pela ineficiência dos serviços que ensejou o fenômeno da judicialização da saúde. Com isso, muitos usuários do SUS ajuízam demandas em face do Poder Público para ter resguardado seu direito fundamental. $\mathrm{O}$ fornecimento de medicamentos é um dos pleitos mais frequentes, de maneira que foi reconhecida a repercussão geral do RE 566.471, cujo julgamento teve início perante o Supremo Tribunal Federal, aguardando a sociedade a definição das diretrizes para situações semelhantes.

Por sua vez, a igualdade é direito fundamental mencionado desde o preâmbulo da Constituição de 1988. É notória a relevância do princípio da igualdade assegurado em 
diversos dispositivos do texto constitucional, entre eles, o art. $5^{\circ}$ que integra o Título II, dos direitos e garantias fundamentais. Robert Alexy (2008, p. 393) analisa o direito geral de igualdade em sua obra Teoria dos Direitos Fundamentais, apresentando perspectivas às vezes ignoradas pelos aplicadores do direito. Com isso, merece ser feita a correlação da estrutura do dever de igualdade na criação do direito exposta por Alexy com a garantia do direito à saúde, nos termos da Constituição Federal brasileira de 1988.

Portanto, a hipótese do trabalho consiste em apresentar um paralelo entre o direito à igualdade geral na visão de Robert Alexy, o direito à saúde garantido pela Constituição e o RE 566.471 a ser apreciado pelo Supremo Tribunal Federal. Com isso, será observado o cumprimento pelas instituições do dever formal e do dever material da igualdade.

\section{O DIREITO GERAL DE IGUALDADE DE ROBERT ALEXY}

Na visão de Robert Alexy o direito geral de igualdade (ALEXY, 2008, p. 396) compreende o dever de igualdade na aplicação do direito e também na sua criação. Ao legislador caberia obedecer a regra geral de que os iguais devem ser tratados igualmente e os desiguais desigualmente. Tal enunciado, entretanto, pode receber duas interpretações distintas a partir da igualdade valorativa. Na explicação dos tratamentos diferenciados Alexy utiliza fórmulas do Tribunal Constitucional Alemão para concluir que é vedado tratar o substancialmente igual desigualmente e também o substancialmente igual arbitrariamente de forma desigual. $\mathrm{Na}$ medida em que todas as razões que poderiam ensejar um tratamento diferenciado são consideradas insuficientes, deve ser concedido obrigatoriamente um tratamento igualitário.

Ao buscar a justificativa para o tratamento inverso, isto é, o dever de tratar desigualmente, Alexy entende que deve existir uma fundamentação procedente que enseje o dever do tratamento desigual (o qual deve ser justificado por princípios contrapostos).

Apesar de existir o receio por parte de alguns doutrinadores de que os juízes passariam a deter competências ilimitadas para decidir sobre as questões de justiça com base no direito geral de igualdade, Alexy desconstrói tal desconfiança. Esse argumento é fragilizado quando se compreende que o enunciado da igualdade é uma lex generalis em relação às normas especiais sobre igualdade, de modo que as "decisões materiais sobre a igualdade" (conduzidas a partir de normas especiais de igualdade) tornam supérflua a solução da questão a partir do 
enunciado geral da igualdade. Ou seja, havendo norma específica à solução do caso, não se aplicará o enunciado geral, que teria papel subsidiário, de orientação geral.

Também podem surgir casos em que não haverá razões suficientes para a admissibilidade e nem para a obrigatoriedade de um tratamento desigual. Quando o enunciado geral da igualdade não exige um tratamento igual nem um tratamento desigual, será permitido tanto um quanto o outro. Nestas situações Alexy enxerga a atribuição da discricionariedade ao legislador e não aos magistrados. Para se garantir maior segurança jurídica nos casos em que o legislador é dotado de discricionariedade pode-se optar por apoiar as decisões em juízos de valor (e nas normas constitucionais), forçando uma argumentação sistemática, ou, ainda, a argumentação baseada em precedentes ou numa justiça sistêmica. Com isso, o criador da lei estaria adstrito não só ao princípio da legalidade como também aos demais princípios positivados no ordenamento jurídico.

A questão de maior desafio enfrentada tanto por Alexy como pelos legisladores é se diante da fórmula "os iguais devem ser tratados igualmente e os desiguais desigualmente" o Estado teria ou não obrigação de criar uma igualdade fática. Para analisar essa responsabilidade primeiramente são estudados os conceitos do tratamento igual nos sentidos jurídico e fático. O tratamento igual e o tratamento desigual podem ser compreendidos tanto em relação a atos como em relação a consequências - quando compreendidos como atos os conceitos conectam-se exclusivamente às ações estatais; e quando compreendidos enquanto consequências, as consequências fáticas da ação estatal são consideradas decisivas. Isto é, se o tratamento é analisado sob o ponto de vista do ato, será avaliado se as partes envolvidas no caso estão faticamente iguais (em equilíbrio) durante a ação estatal. Porém, se o tratamento for analisado na perspectiva da consequência gerada pela conduta estatal, será sopesado o resultado alcançado pelas partes (se a interferência favoreceu ou não a isonomia).

Alexy expõe em seu texto a ideia do Tribunal Constitucional Federal alemão sobre os princípios da igualdade jurídica e da igualdade fática. Na visão daquela Corte a promoção de determinados grupos significa por si só o tratamento dos outros de forma desigual. Isto é, a promoção da igualdade fática está atrelada à aceitação da desigualdade jurídica. Não há dúvidas de que o princípio da igualdade jurídica não deve ser abandonado em favor do princípio da igualdade fática, posto que aquele que decide sobre a igualdade no caso concreto tem visão incompleta do processo de fomento dessa igualdade e pode controlá-lo apenas parcialmente. 
Para que o princípio da igualdade fática seja concretizado, é necessária a sua compreensão como um direito subjetivo do indivíduo plenamente vinculante e também exigível judicialmente. Neste ponto, merecem ser citadas as palavras de Robert Alexy:

\begin{abstract}
Tudo isso deixa claro que a classificação do princípio da igualdade fática como uma possível razão suficiente para a obrigatoriedade de um tratamento jurídico desigual que sirva ao fomento de uma igualdade fática não implica nem que a igualdade jurídica ou a liberdade negativa sejam injustificadamente suplantadas pela igualdade fática, nem que a competência para a configuração da ordem social seja transferida em um grau inadmissível do legislador para o Tribunal Constitucional Federal.
\end{abstract}

Na visão de Alexy, se a igualdade fática é atingida por meio de tratamento jurídico desigual, o princípio da igualdade jurídica está sofrendo restrição. Assim, quando um tribunal decide criar a igualdade fática deve observar o conjunto de princípios colidentes que estão sendo conformados para viabilizar a situação almejada (técnica da ponderação).

O argumento exposto por Alexy sobre a igualdade fática e sua forma de concretização pelo Tribunal Constitucional se assemelham às discussões da doutrina brasileira sobre o ativismo judicial e decisões garantidoras de direitos (principalmente) sociais. O filósofo, inclusive, traz ideia bastante pertinente para o cenário de judicialização dos direitos ao afirmar que a intervenção nas competências do legislador se torna ainda mais grave quando a atividade jurisdicional que visa à igualdade fática não se limita a intervir apenas na discricionariedade jurídica do legislador, mas adentra também em sua discricionariedade financeira. A ressalva feita por Alexy provoca remissão inevitável às decisões proferidas por magistrados que determinam o bloqueio de contas de entes federativos para a reserva de recursos destinados a um fim especificado em sua decisão. A atualidade do tema é percebida pela recente pauta de julgamento do Supremo Tribunal Federal que iniciou a apreciação de ação cujo objeto é a concessão de medicamentos de alto custo pelos entes federativos como resultado de demandas judiciais propostas por particulares. $\mathrm{O}$ caso merece maior detalhamento a ser tratado em tópico seguinte, por possuir estreita correlação com o debate entre a igualdade fática e jurídica.

Voltando à estrutura dos direitos de igualdade como direitos subjetivos, Alexy cita Gerhard Leibholz ${ }^{162}$ ao atribuir ao enunciado geral da igualdade uma natureza negativa, constituindo ele num direito a uma abstenção. Porém, também podem ser apontados direitos ligados ao enunciado geral de igualdade que possuem status positivo, isto é, que demandam uma ação para que sejam concretizados. Por fim, depois de sugerir uma das classificações possíveis do direito geral de igualdade (em direitos de igualdade definitivos abstratos, direitos

\footnotetext{
162 Jurista alemão defensor da democracia que compôs o Tribunal Constitucional da Alemanha de 1951 a 1971.
} 
de igualdade definitivos concretos e direitos de igualdade prima facie abstratos), Alexy conclui que o mais importante é compreendê-lo como um feixe de direitos subjetivos, que pode assumir diversos formatos.

\section{A UNIVERSALIDADE E IGUALDADE DE ACESSO AOS SERVIÇOS DE SAÚDE E A INTEGRALIDADE DE ASSISTÊNCIA}

A Constituição Federal de 1988 assegura em seu art. 196 a saúde como direito de todos e dever do Estado, devendo as políticas sociais e econômicas dar acesso universal e igualitário às ações e serviços para sua promoção, proteção e recuperação. Em seguida, o art. 197 permite que a execução seja feita diretamente ou através de terceiros e, também, por pessoa física ou jurídica de direito privado. Por fim, o art. 198 do texto constitucional afirma que as ações e serviços públicos de saúde devem seguir a diretriz de atendimento integral.

O texto constitucional é claro ao garantir a saúde a todas as pessoas independentemente do preenchimento de qualquer requisito, incluindo até mesmo os nãobrasileiros. O financiamento dos serviços será de responsabilidade da União, Estados, Distrito Federal e Municípios, com observância dos percentuais prescritos na própria Constituição.

A Lei $n^{\circ} 8.080 / 1990$ foi editada com o objetivo de regular as condições para a promoção, proteção e recuperação da saúde, a organização e o funcionamento dos serviços correspondentes, complementando o texto constitucional. Em seu art. $7^{\circ}$ são reforçados os princípios que devem orientar a prestação dos serviços de saúde, entre eles a universalidade de acesso, a integralidade de assistência e a igualdade da assistência à saúde, sem preconceitos ou privilégios de qualquer espécie. Porém, o desrespeito a tais princípios é patente na realidade brasileira.

A universalidade de acesso aos serviços de saúde deve existir em todos os níveis de assistência, constituindo promessa ampla do Estado brasileiro. De modo a viabilizar a prestação da saúde para a parcela da população que de fato necessita do serviço público essas diretrizes precisam ser adequadas à realidade financeira e estrutural do país. Com isso, o acesso é universal e a assistência deve ser prestada integralmente àqueles que mais necessitem, sob pena da igualdade permanecer apenas do nível teórico e não alcançar o campo fático. Mostra-se inviável, por exemplo, garantir a integralidade das ações e serviços em todos os níveis de complexidade do sistema. Não há país que sustente tal compromisso. 
Desse modo, é indiscutível a obrigatoriedade da prestação da saúde pelo Estado brasileiro, com auxílio dos três níveis federativos, sendo fundamental o suporte das demais instituições sociais. O judiciário tem participado intensamente deste setor e sua colaboração poderia ser otimizada ao invés de rechaçada, uma vez que já criou raízes.

\section{O PRINCÍPIO DA IGUALdADE NA SAÚdE PELO SUPREMO TRIBUNAL FEDERAL}

O Supremo Tribunal Federal reconheceu a repercussão geral em dois recursos extraordinários (566.471 e 657.718) que debatem a possibilidade de o Estado ser compelido a fornecer medicamentos a sujeito que não possui condições financeiras para custeá-lo, à luz do direito fundamental à saúde. O tema tratado nas duas ações é recorrente nos tribunais brasileiros que são constantemente demandados a decidir sobre a viabilidade de o Estado custear os mais variados tratamentos de saúde.

A Advocacia-Geral da União se manifestou por meio de Consultoria Jurídica promovida em prol do Ministério da Saúde sobre o panorama da judicialização da saúde no âmbito da Justiça Federal e produziu apontamentos na seara das Justiças Estaduais ${ }^{163}$. O documento possui o intuito de compilar informações acerca da intervenção judicial no serviço de saúde para que se tenha dimensão, ainda que precária, do impacto da questão em âmbito nacional $^{164}$. O resultado do levantamento dos processos ativos em 2013 indica que os gastos decorrentes das demandas judiciais somavam aproximadamente 1 bilhão de reais, o que corresponde a praticamente $1 / 7$ do orçamento da saúde para atendimento de todos os usuários do SUS no ano de 2010 (de R\$ 6,9 bilhões de reais). Ressalte-se que foram computados apenas os valores informados pela União e os Estados de Goiás, Santa Catarina, São Paulo, Pará, Paraná, Pernambuco, Minas Gerias, Tocantins e Alagoas, sendo excluídos os outros 17 Estados, o DF e todos os Municípios.

Tal pesquisa enfatiza a relevância do tema a ser decidido pelo Supremo Tribunal Federal. A igualdade fática dos usuários do serviço público de saúde não parece estar sendo assegurada pela judicialização das demandas. Como concluiu a Advocacia-Geral da União, é

\footnotetext{
163 Ministério da Saúde. Intervenção Judicial na saúde pública: Panorama no âmbito da Justiça Federal e Apontamentos na seara das Justiças Estaduais. 2013. Disponível em: <http://portalsaude.saude.gov.br/images/pdf/2014/maio/29/Panorama-da-judicializa----o---2012---modificadoem-junho-de-2013.pdf>. Acesso em: 28 nov. 2016.

${ }^{164}$ Os dados que instruem o documento foram atualizados até maio de 2013.
} 
inegável a legitimidade dos interesses pleiteados nessas demandas, porém, isso não afasta a individualidade dos direitos discutidos. Portanto, os pleitos têm impactado de modo expressivo na programação e na organização do Sistema Único de Saúde, de modo que a Corte Suprema deve se pronunciar quanto à ponderação entre os interesses individuais e a percepção coletiva do direito à saúde.

\subsection{A igualdade jurídica e fática no julgamento do RE 566.471}

O Ministro Luís Roberto Barroso proferiu voto-vista no RE 566.471 em que reconhece a necessidade de se desjudicializar a prestação do serviço de saúde no Brasil. Chama atenção para o fato de que "nenhum país do mundo oferece todo o tipo de medicamento e todo o tipo de tratamento a todas as pessoas". A discussão não gira em torno da ponderação entre o direito à saúde e à vida, de um lado, e a separação de Poderes e regras orçamentárias, de outro lado, mas sim entre vida e saúde de uns versus vida e saúde de outros. Isso porque os recursos financeiros são limitados e a necessidade de alocação é imperiosa.

Desse modo, as decisões judiciais que condenam a Administração a fornecer tratamentos produzem efeitos além das partes envolvidas, pois acarretam gastos imprevisíveis, insegurança jurídica (não garantia de julgamento uniforme) e o mau funcionamento da justiça que não possui a infraestrutura necessária para analisar tecnicamente os pedidos. Com isso, a seletividade resultante da interferência judicial contribui para a violação da igualdade jurídica prometida pela Constituição Federal, uma vez que as decisões judiciais beneficiam as partes da ação, mas não garantem a universalização do direito. $\mathrm{Ou}$ seja, o judiciário tem contribuído para a coexistência de duas realidades no SUS: a ineficiência do serviço prestado à generalidade da população e o pontual recebimento de medicamentos/serviços pelos indivíduos que ajuizaram ações contra o Estado.

Como defende o Ministro Barroso, a questão vai além da "reserva do possível". Logicamente, é inevitável a adequação da concretização dos direitos sociais (entre eles o direito à saúde) com as possibilidades orçamentárias. Em outros termos, não se pode exigir do Estado o impossível ou o irrealizável. Gustavo Amaral ${ }^{165}$ defende que a justiça do caso concreto deve ser sempre aquela que possa ser assegurada a todos que estão ou possam vir a estar em situação similar, sob pena de quebrar-se a isonomia. Isso não significa a ineficácia ou

\footnotetext{
165 AMARAL, Gustavo. Direito, escassez e escolha: Critérios Jurídicos para lidar com a escassez de recursos e as decisões trágicas. 2. ed. São Paulo: Lumen Juris, 2010.
} 
não aplicabilidade imediata do direito, mas indica a necessidade da ponderação entre princípios.

A reserva do possível não deve ser traduzida como uma negativa de efetividade dos direitos sociais, de modo que não serve como discurso padrão para a improcedência de demandas judiciais que pleiteiam medicamentos. Ao apreciar a ADPF 45 o Ministro Celso de Mello tratou dos conceitos da reserva do possível e do mínimo existencial, sintetizando o primeiro deles no seguinte binômio: os condicionamentos impostos pela reserva do possível impõem de um lado que a pretensão individual (ou social) deduzida em face do Poder Público seja razoável, bem como que haja a disponibilidade financeira do Estado para tornar efetivas as prestações reclamadas.

Na visão de Ingo Wolfgang Sarlet ${ }^{166}$, a implementação de políticas públicas pode ser, excepcionalmente, atribuída ao Poder Judiciário quando os órgãos estatais competentes não cumprem seus encargos político-jurídicos, de modo a comprometer a eficácia e a integridade de direitos individuais e/ou coletivos. Com perspectiva diversa, Gustavo Amaral defende que a competência do Poder Judiciário se limita ao controle das razões dadas pelo Estado ao fazer suas escolhas (aos magistrados caberia ponderar o grau de essencialidade da pretensão e o grau de excepcionalidade do caso concreto).

O Ministro Barroso defende no voto vista proferido no RE 566.471 que as decisões alocativas de recursos na área da saúde devem ser tomadas pelos órgãos competentes para a elaboração das políticas públicas de saúde. No entanto, a judicialização excessiva da saúde tem retirado o espaço para a realização das políticas públicas, prejudicando, inclusive, a legitimidade democrática das decisões tomadas. Também critica a preferência pela satisfação dos interesses individualistas e elitistas, na medida em que ao atender aos pleitos dos litigantes deixa a Administração de satisfazer o interesse social do restante da população, ficando em pior situação a parcela mais pobre que sequer acessa o Judiciário. Por último, trata da capacidade institucional que faltaria ao Poder Judiciário para compreender o panorama geral da prestação da saúde, de modo que ao decidir em favor de um jurisdicionado pode estar lesando o direito de terceiros. Conclui que o "grande desafio em matéria de saúde é, portanto, o de saber em que circunstâncias deverá ter lugar tal interferência”. Nesse ponto verifica-se o paralelo entre a ideia de Robert Alexy de criação da igualdade fática por meio da interferência do magistrado e a consequente restrição da igualdade jurídica.

\footnotetext{
${ }^{166}$ SARLET, Ingo Wolfgang. A eficácia dos direitos fundamentais: uma teoria geral dos direitos fundamentais na perspectiva constitucional. 12. ed. São Paulo: Livraria do Advogado, 2015.
} 
O modelo brasileiro de assistência pública de saúde é amplo e, conforme o art. $7^{\circ}$ da Lei $\mathrm{n}^{\mathrm{o}}$ 8.080/1990, engloba a integralidade de assistência, incluindo as "ações e serviços preventivos e curativos, individuais e coletivos, exigidos para cada caso em todos os níveis de complexidade do sistema". Portanto, a raridade da enfermidade ou especificidade do tratamento não afasta a obrigatoriedade de assistência. O Ministro Luís Roberto Barroso sugere alguns parâmetros mínimos para auxiliar na decisão se e em que condições o Poder Judiciário pode deferir a dispensação gratuita de medicamentos, independentemente de custo.

Caso o medicamento já tenha sido incorporado pelo Sistema Único de Saúde para dispensação gratuita, ao Judiciário caberá somente efetivar a política pública já formulada pelo órgão competente. Nesta situação qualquer cidadão detém o direito subjetivo público de pleitear o medicamento, desde que exista a necessidade do paciente e a prévia solicitação à Administração (com negativa ou demora injustificada). Tais condicionamentos pretendem evitar que o Judiciário seja a primeira opção do administrado ao buscar seu direito à saúde. A Administração, logicamente, deve demonstrar maior aptidão na solução dos pleitos.

Entretanto, quando o fármaco não consta na lista de itens fornecidos pelo SUS, Barroso reconhece a ausência de consenso suficiente para que a Corte Suprema determine a impossibilidade de deferimento do pedido. É neste ponto que se aprofunda a complexidade do tema. O Ministro do STF vota no sentido de que não seria apropriado impedir juízes e tribunais ordinários de determinar o fornecimento de medicamentos não padronizados na generalidade dos casos. Para isso, sugere a observância de cinco requisitos pelo magistrado antes de decidir favoravelmente à prestação de saúde.

\section{OS REQUISITOS PARA A DECISÃo FAVORÁVEL À PRESTAÇÃo DO SERVIÇO DE SAÚDE}

A preservação da segurança jurídica e a garantia da igualdade fática dos administrados impele o magistrado a observar condições preestabelecidas na análise dos casos concretos que pleiteiam o direito à saúde. Ao proferir o voto vista no RE 566.471 o Ministro Barroso sugere os seguintes requisitos cumulativos:

(i) a incapacidade financeira do requerente para arcar com o custo correspondente, (ii) a demonstração de que a não incorporação do medicamento não resultou de decisão expressa dos órgãos competentes, (iii) a inexistência de substituto terapêutico incorporado pelo SUS, (iv) a comprovação de eficácia do medicamento 
pleiteado à luz da medicina baseada em evidências, e (v) a propositura da demanda necessariamente em face da União.

De acordo com a análise do jurista, o sujeito somente detém o direito de requerer o medicamento caso demonstre a impossibilidade de arcar com a despesa por si. A prova de hipossuficiência, diferentemente do que se pode imaginar, não viola a universalidade do direito à saúde, mas a assegura, na medida em que o Estado não teria condições econômicas de ofertar todos os medicamentos para toda a população. Assim, deve ser priorizada a prestação de medicamentos àqueles que sem o auxílio do Estado não teriam acesso ao tratamento. Este argumento também se sustenta no princípio da solidariedade social, extraído do $\operatorname{art.} 3^{\circ}$, I, da Constituição Federal.

O jurisdicionado também deve demonstrar a ausência de decisão expressa do órgão competente negando a inclusão do fármaco na lista dos itens a serem fornecidos pelo SUS. Esta condição pretende evitar que a decisão do magistrado se sobreponha à decisão técnica do órgão capacitado que por razões devidamente fundamentadas tenha optado pelo não fornecimento.

O terceiro requisito é a inexistência de substituto terapêutico incorporado pelo SUS. Priorizando a concessão dos medicamentos já dispensados pelo SUS são favorecidas a economicidade e também o princípio da integralidade (haverá mais chances de atender a um maior número de demandas).

Outra condição a ser imposta pelo julgador é a comprovação de eficácia do medicamento a partir de evidências. Isto é, não devem ser deferidos pleitos cujo objeto esteja em estágio experimental. Tal conduta transformaria o Estado num financiador universal de qualquer tipo de tratamento de acordo com a crença pessoal de cada cidadão, prejudicando a igualdade fática.

Por último, as demandas que pleiteiam medicamentos não incorporados pelo SUS devem ser ajuizadas exclusivamente em face da União, pois somente ela tem a competência para decidir sobre a incorporação ou não de uma nova tecnologia em saúde, de acordo com a Lei $n^{\circ}$ 8.080/1990 (através da CONITEC e do Ministério da Saúde). Portanto, apesar de os Estados e Municípios também serem responsáveis pela prestação do serviço de saúde à população, nos casos de medicamentos não incluídos na lista do SUS, a legitimidade passiva é necessariamente da União. 
O mínimo existencial é o fundamento mais comum às demandas que buscam a concretização dos direitos sociais, entre eles, o fornecimento de medicamentos ou serviços ligados à saúde. O termo surgiu no Tribunal Constitucional Alemão quando em 1951 reconheceu o direito constitucional à assistência social. No ano de 1975 foi mais explícito e reconheceu o direito às condições mínimas de uma existência digna, mas somente alguns anos mais tarde reconheceu o próprio direito ao "mínimo existencial".

Para Paulo Gilberto Cogo Leivas ${ }^{167}$, a mais completa definição de mínimo existencial foi formulada por Corinna Treisch nas seguintes palavras:

\begin{abstract}
O mínimo existencial é a parte do consumo corrente de cada ser humano, seja criança ou adulto, que é necessário para a conservação de uma vida humana digna, o que compreende a existência de vida física, como a alimentação, vestuário, moradia, assistência de saúde, etc. (mínimo existencial físico) e a necessidade espiritualcultural, como educação, sociabilidade, etc. Compreende a definição do mínimo existencial tanto a necessidade como também cultural-espiritual, então se fala de um mínimo existencial cultural.
\end{abstract}

Como se vê, o âmbito do mínimo existencial é ajustável conforme a visão de cada doutrinador, sendo um conceito jurídico indeterminado que pode ter significado mais concreto ou abstrato. O Ministro Celso de Mello no julgamento da ADPF 45 defendeu a "necessidade de preservação, em favor dos indivíduos, da integridade e da intangibilidade do núcleo consubstanciador do mínimo existencial". Mas a fixação do mínimo existencial pode ser relativa para cada indivíduo.

No julgamento do RE 566.471 o Ministro Barroso não empregou o conceito do mínimo existencial (com exceção da passagem em que cita o posicionamento do Ministro Marco Aurélio) ao tratar do direito à saúde. Ao analisar o direito fundamental o magistrado preferiu se ater a conceitos como a necessidade, a ponderação de princípios e a igualdade entre os usuários. O resultado dessa opção parece ser um voto mais robusto, a partir do qual podem ser extraídas diretrizes para a atuação dos gestores e magistrados dos tribunais ordinários.

A vedação ao retrocesso social é outra ideia construída pela doutrina que sintetiza a eficácia negativa das normas constitucionais. Em sua essência, pretende a teoria impedir que sejam editadas ou interpretadas normas já existentes em sentido contrário às garantias dos direitos fundamentais. Portanto, atua contra a supressão ou diminuição dos direitos sociais.

${ }^{167}$ LEIVAS, Paulo Gilberto Cogo. Teoria dos Direitos Fundamentais Sociais. 1. ed. São Paulo: Livraria do Advogado, 2006. p. 135. 
Alguns defendem que a vedação ao retrocesso gozaria de autonomia parcial por depender de outros conceitos para ter significado compreendido devidamente. Assim, assume estreita relação com a dignidade da pessoa humana e o mínimo existencial, além de reforçar a segurança jurídica na aplicação dos direitos fundamentais. A ideia da proibição vai além do direito adquirido, da coisa julgada e das demais figuras que vedam comportamentos retroativos. A doutrina parece ter pretendido aproximar seu conceito da estabilidade diferenciada que possuem os direitos fundamentais sociais previstos nas cláusulas pétreas na Constituição de 1988.

Ao proteger a dignidade da pessoa humana, o mínimo existencial e a segurança jurídica na aplicação dos direitos fundamentais, a vedação ao retrocesso conecta-se ao princípio do Estado Democrático do Direito (que determina a manutenção de patamar mínimo de proteção social).

A vedação ao retrocesso abrange a ação de interpretação e aplicação do texto normativo, de modo que ainda que não exista a alteração expressa do texto normativo, não são aceitas mutações de sentido que restrinjam o sentido das normas.

Porém, são aceitas medidas de cunho retrocessivo, desde que se justifiquem através de suporte constitucional, preservando-se o núcleo essencial dos direitos sociais. Como orientação do princípio da proporcionalidade, deve ser evitada a intervenção excessiva no caso concreto, da mesma forma que a proteção insuficiente do direito.

No julgamento do RE 566.471 mesmo que o Supremo Tribunal Federal decida pela ausência de obrigação do Estado brasileiro de fornecer o medicamento pleiteado, o direito à saúde não terá sofrido retrocesso social ou violação de seu conteúdo mínimo. Isto porque o entendimento estaria embasado em princípios constitucionais de mesma magnitude, como é o direito à igualdade.

Além disso, os sistemas de saúde, por serem construções sociais, devem se adequar aos contextos históricos e aos fatores supervenientes que interfiram em seu funcionamento. Ou seja, a economicidade da prestação da saúde não pode ser ignorada, sob pena de ser desrespeitada outra diretriz do Sistema Único de Saúde, qual seja, a universalidade.

\section{CONSIDERAÇÕES FINAIS}

A prestação da saúde tem motivado a reestruturação da máquina administrativa brasileira que busca viabilizar a eficiência do serviço disponibilizado para a população. Foram 
editadas leis com novos vínculos entre o Estado e entidades privadas que parecem ainda não ter alcançado seus objetivos. Para incrementar a complexidade do tema o Judiciário tem interferido corriqueiramente nas decisões de política pública, misturando a discricionariedade administrativa com escolhas técnicas e a legalidade jurídica.

A apreciação do tema pelo Supremo Tribunal Federal poderá trazer importantes diretrizes para os magistrados das instâncias inferiores, além de constituir um guia de conduta para os gestores. De fato, as demandas pleiteando o fornecimento de medicamentos (entre outras relacionadas a tratamentos de saúde) interferem nos orçamentos públicos (principalmente nos estaduais e municipais que são mais enxutos) e devem seguir orientação uniforme do Judiciário para que sejam asseguradas a igualdade fática e jurídica presentes no texto Constitucional.

$\mathrm{Na}$ conclusão do seu voto vista o Ministro Barroso firmou a tese em sede de repercussão geral no sentido de que o Estado não pode ser obrigado por decisão judicial a fornecer medicamento não incorporado pelo SUS, independentemente de custo, salvo hipóteses excepcionais. Nestes casos há a necessidade de preenchimento de cinco requisitos cumulativos que pretendem restringir as concessões a partir dos seguintes critérios: a) a incapacidade financeira do sujeito de arcar com o custo do medicamento; b) o dever de demonstração de ausência de decisão expressa dos órgãos competentes pela negativa da incorporação do medicamento; c) a impossibilidade de substituição por terapêutico diverso incorporado pelo SUS; d) a comprovação de eficácia do medicamento, a partir de evidências concretas da ciência médica; e e) a necessidade de propor a demanda em face da União, considerando que é o ente federativo competente para a incorporação de novos medicamentos no sistema, de acordo com a lei regulamentadora do SUS.

Além das cinco condições a serem checadas em cada situação, o Ministro apontou em sua conclusão um parâmetro procedimental a ser observado pelo magistrado. Para Barroso, é imperiosa a participação de entes ou pessoas com expertise técnica na área da saúde junto ao Poder Judiciário para auxiliá-lo na aferição dos requisitos de fornecimento do medicamento. E, posteriormente, na comunicação entre o Judiciário e os órgãos competentes para a recomendação da análise da viabilidade de sua incorporação no âmbito do SUS.

Buscou o jurista afastar critérios subjetivos ao prescrever um passo-a-passo a partir de constatações fáticas ou documentais. Com isso, será garantida a segurança jurídica na jurisprudência brasileira ao apreciar casos semelhantes e também a proteção da igualdade fática dos cidadãos. 
O julgamento do Recurso Extraordinário 566.471 pelo Supremo Tribunal Federal é aguardado por vários setores sociais e representará um marco na conduta da Administração e do Poder Judiciário.

\title{
REFERÊNCIAS
}

ALEXY, Robert. Teoria dos Direitos Fundamentais. São Paulo: Malheiros, 2008. (Teoria \& direito público). Tradução de Virgílio Afonso da Silva.

AMARAL, Gustavo. Direito, escassez e escolha: Critérios Jurídicos para lidar com a escassez de recursos e as decisões trágicas. 2. ed. São Paulo: Lumen Juris, 2010.

LEIVAS, Paulo Gilberto Cogo. Teoria dos Direitos Fundamentais Sociais. 1. ed. São Paulo: Livraria do Advogado, 2006.

SARLET, Ingo Wolfgang. A eficácia dos Direitos Fundamentais: uma teoria geral dos direitos fundamentais na perspectiva constitucional. 12. ed. São Paulo: Livraria do Advogado, 2015 .

SILVA, Rodrigo Zouain da. O direito constitucional à saúde pública e a integralidade de assistência: colisão-ponderação entre o princípio da proibição do retrocesso social e o princípio da reserva do possível. Disponível em: <http://www.ambitojuridico.com.br/site/index.php?n_link=revista_artigos_leitura\&artigo_id=10912>. Acesso em: 23 nov. 2016.

WANG, Daniel Wei Liang. Escassez de recursos, custos dos direitos e reserva do possível na jurisprudência do STF. Revista Direito GV, São Paulo, n. 4(2), p.539-568, Jul-Dez/2008.

\section{EQUAL RIGHTS ON ALEXY AND THE MEDICINES CASE THROUGH THE SUPREME FEDERAL COURT}

\begin{abstract}
This paper analyzes the right to health, which is one of the fundamental rights listed by the Federal Constitution, and the State has the duty to ensure universal and equal access to actions and services for the promotion, protection and recovery of health. The complexity of the provision of the health service comes up when the
\end{abstract}


incapacity of the Administration to provide it in an integral way for the whole society is realized. The judicialization of health was caused by the inefficiency of the service, since the individuals started to ask for the Judiciary interference for the resolution of each case. However, by solving the individualized situations, the magistrate assumes the risk of violating isonomy, making breaches for injustices. Robert Alexy in Theory of Fundamental Rights deals with the general right of equality and brings forward the concepts of social equality and legal equality that must be ensured by the legislator and the judicial courts. So, a parallel is constructed between Alexy's Theory of the social and legal equality and the case of the suppling medicines that is pending of judgment by the Supreme Federal Court. The recognition of the general repercussion in RE 566.471 shows the relevance of the subject to the Brazilian society that longs for the even treatment among the Unified Health System users.

Keywords: Right to health. Equality. Alexy. Medicines. STF. 